\title{
Leuco-erythroblastosis following withdrawal from glucocorticoid therapy
}

\author{
P. M. TRENCHARD \\ B.Sc., M.B., Ch.B., M.I.Biol. \\ C. E. Wells \\ M.B., Ch.B., F.R.C.P. \\ A. G. S. JARRIWALla \\ M.B., Ch.B., M.R.C.P. \\ Departments of Haematology and Neurology, University Hospital of Wales, Cardiff
}

\begin{abstract}
Summary
Leuco-erythroblastosis has many known associations (Burkett, Cox and Fields, 1965; Weick, Hagedorn and Linman, 1974; Retief, 1964), but the only ones related to drug therapy are the well established response to haematinics (Burkett et al., 1965) and one possible case following anti-epileptic therapy (Retief, 1964). The case described below is of leuco-erythroblastosis following steroid withdrawal in a young man with primary polymyositis.
\end{abstract}

\section{Case report}

At 22 years of age this previously fit patient developed progressive lower limb weakness such that ,3 years later in December 1972 he presented with all the signs and symptoms of chronic polymyositis of unknown cause. This was confirmed by very high serum concentrations of creatine phosphokinase (CPK) and aldolase and by typical findings on electromyography and in the muscle biopsy. Syphilis, myasthenia, neoplasia and thyroid disorder were all excluded, and the initial basal blood counts were normal: haemoglobin $16 \mathrm{~g} / \mathrm{dl}$ and leucocytes $4 \cdot 8-x 10^{\circ} / 1$.

Glucocorticoid therapy was started in March 1973 at a dose of $40 \mathrm{mg}$ prednisone daily, increasing to $80 \mathrm{mg}$. There was no improvement in strength, no reduction of the serum CPK concentrations and the patient became Cushingoid eventually requiring antihypertensive therapy. Clinical improvement was only achieved by the addition of azathioprine $75 \mathrm{mg}$ daily in August 1973 when prednisone at a daily dose of 20-50 mg was found to exert a synergistic effect. During August 1975, however, high dose glucocorticoid therapy was used (dexamethasone equivalent to $160 \mathrm{mg}$ prednisone daily) in an attempt to withdraw azathioprine. Weakness more marked than

Correspondence: Dr Paul M. Trenchard, Department of Haematology, University Hospital of Wales, Heath Park, Cardiff CF4 4XW. at presentation developed rapidly, necessitating an increase in azathioprine dose to $200 \mathrm{mg}$ daily and concurrent withdrawal of the high dose steroid regime. This was followed almost immediately by the disappearance of the symptoms and signs of polymyositis.

The leucocyte and haemoglobin concentrations paralleled the steroid dosage with some very significant fluctuations (Fig. 1). The former lay persistently above the basal level. In contrast, the haemoglobin concentration fell significantly below the basal leve on two occasions, producing haemoglobin 'troughs' each of which followed a $50 \%$ reduction in steroid dosage a few days earlier. All other steroid reductions were considerably less than this. The basal level was regained and exceeded within a few weeks (Fig. 1).

As the leucocyte and haemoglobin concentrations fell significantly (Fig. 1), so immature forms appeared in the peripheral blood. After halving the daily prednisone dose from $80 \mathrm{mg}$ this was only apparent in the myeloid series, whereas halving from the equivalent of $160 \mathrm{mg}$ led to additional erythroid involvement (Fig. 1). The platelet concentration also rose on these two occasions, particularly the latter, when a maximum concentration of $360 \times 10^{9} / 1$ was noted. Other platelet concentrations lay between 130 and $305 \times 10^{\%} / 1$ and showed no correlation with increasing glucocorticoid dosage. This leucoerythroblastosis coincided with frank psychosis which had progressed from milder psychotic symptoms over the preceding 5 days and responded immediately to haloperidol. The polymyositis was very well controlled throughout this period by azathioprine, and no previously described cause for the leuco-erythroblastosis could be found. Acute blood loss was excluded clinically, neoplasia was excluded radiologically, and haemolysis was excluded by the absence of jaundice, the absence of increased urine urobilinogen, a negative Coombs test and normal serum haptoglobin levels. 


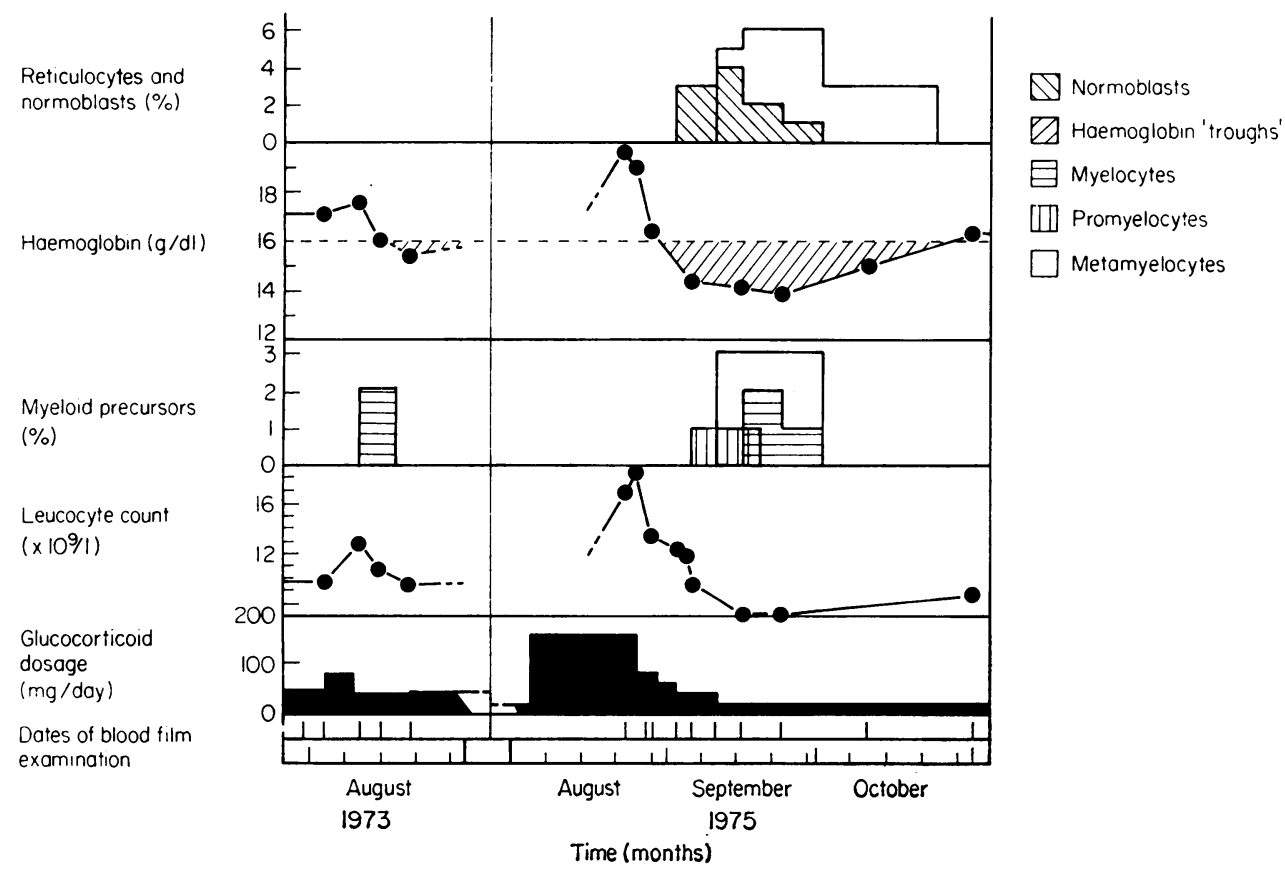

Fig. 1. Effect of glucocorticoid dosage (as prednisone equivalent) on some cellular components of the peripheral blood.

The patient is now well, and maintained on azathioprine $200 \mathrm{mg}$ daily, dexamethasone $2 \mathrm{mg}$ daily and oxyprenolol $640 \mathrm{mg}$ daily and has a normal blood film.

\section{Discussion}

When leuco-erythroblastosis and polymyositis occur together they are invariably secondary to neoplastic disease-not found in this patient-and there are no reported cases in the literature of primary polymyositis producing leuco-erythroblastic change (Mulder et al., 1963; de Vere and Bradley, 1975). This suggests that the polymyositis may be incidental in this patient. The case shows, however, that azathioprine may be the treatment of choice in this disease if moderate steroid dosage fails, perhaps combined with the latter for a probable synergistic effect. This would be in preference to high dose steroids which may themselves produce significant muscle weakness. The problem would lend itself to future therapeutic trials.

The haematological changes in this patient are clearly connected with glucocorticoid therapy-the direct proportionality of the leucocyte concentration being well known, with some well established mechanisms (Athens et al., 1961; Bishop et al., 1968). The mechanisms for a similar proportionate rise in the haemoglobin concentration are, in contrast, poorly delineated. Changes in plasma volume may play a part (Kleeman et al., 1960; Glader, Rambach and Alt, 1968) as may changes in the red cell mass (Glader et al., 1968; Peschle et al., 1974). Such mechanisms need more complete investigation since the precipitous fall in the haemoglobin concentration after steroid withdrawal in this patient implies a significant plasma volume effect.

The leuco-erythroblastosis is fascinating, particularly since the case described by Retief (1964) following anti-epileptic therapy could equally be attributed to steroid withdrawal-glucocorticoids having been added to control hepato-cellular jaundice, with their subsequent withdrawal. One possible mechanism implied by the data in Fig. 1 is that at a given steroid dose new leucocyte and haemoglobin concentrations are established which become accepted by the body as 'normal'. Significant steroid reduction allows a return to lower concentrations. This change is presumably so rapid that although the latter lie in the normal range the homeostatic mechanisms interpret the fall as abnormal so that the feedback inhibition of marrow precursor cell release is removed, resulting in leucoerythroblastosis.

Little is known of the mechanism whereby 
retention of precursor cells by the bone marrow is regulated. This case suggests that future experiments using steroid administration and withdrawal may help in their elucidation.

\section{References}

Athens, J.W., HaAb, O.P., RaAb, S.O., Mauer, A.M., Ashenbrucker, H., Cartwright, G.E. \& Wintrobe, M.M. (1961) Leukokinetic studies. IV. The total blood, circulating and marginal granulocyte pools and the granulocyte turnover rate in normal subjects. Journal of Clinical Investigation, 40, 989.

Bishop, C.R., Athens, J.W., Boggs, D.R., WARner, H.R., Cartwright, G.E. \& Wintrobe, M.M. (1968) Leukokinetic studies. XIII. A non-steady state kinetic evaluation of the mechanism of cortisone-induced granulocytosis. Journal of Clinical Investigation, 47, 249.

BurketT, L.L., Cox, M.L. \& FieldS, M.L. (1965) Leucoerythroblastosis in the adult. The American Journal of Clinical Pathology, 44, 494.

de Vere, R. \& Bradley, W.G. (1975) Polymyositis: its presentation, morbidity and mortality. Brain, 98, 637.
Glader, B.E., Rambach, W.A. \& Alt, H.L. (1968) Obser vations on the effect of testosterone and hydrocortisone on erythropoiesis. Annals of the New York Academy of Sciences, 149, 383.

Kleeman, C.R., Koplowitz, J., Maxwell, M.H., Cutler, R. \& Dowling, J.T. (1960) Mechanisms of impaired water excretion in adrenal and pituitary insufficiency. Journal of Clinical Investigation, 39, 1472.

Mulder, D.W., WinkelmanN, R.K., Lambert, E.H., Diessner, G.R. \& Howard, F.M. (1963) Steroid therapy in patients with polymyositis and dermatomyositis. Annals of Internal Medicine, 58, 969.

Peschle, C., Marone, G., Genovese, A., Sacchetti, L. \& Condorelli, M. (1974) The hormonal influences on red cell production: physiological significance and mechanism of action. Erythropoiesis. In: Proceedings of the Fourth International Conference on Erythropoiesis, p. 99. University Park Press, Tokyo.

Retief, F.P. (1964) Leuco-erythroblastosis in the adult. Lancet, i, 639.

Weick, J.K., Hagedorn, A.B. \& Linman, J.W. (1974) Leuco-erythroblastosis. Proceedings. Mayo Clinic, 49, 110.

\section{A case of paraparesis due to extramedullary haemopoiesis in HbE-thalassaemia}

\author{
J. C. L. MihindukulasuriYa* \\ M.D.
}

$$
\begin{aligned}
& \text { V. MACHADO* } \\
& \text { M.D. }
\end{aligned}
$$

\author{
D. Chanmugam* \\ M.D., M.R.C.P.
}

\author{
C. A. Samarasinghe $\dagger$ \\ M.B., B.S.
}

\author{
P. A. M. KYNOCH \\ *Department of Medicine, Faculty of Medicine, University of Sri Lanka, Colombo Campus, \\ $\dagger$ Neurosurgical Unit, General Hospital Colombo, and ${ }_{\ddagger}$ Department of Clinical Biochemistry, \\ University of Cambridge
}

\section{Summary}

A 24-year-old female with haemoglobin E-thalassaemia who presented with paraparesis of 18 months' duration was found to have spinal extradural extramedullary haemopoietic tissue extending from T4 to T9. Complete neurological recovery followed laminectomy. The importance of prompt diagnosis and treatment, of this unusual complication of extramedullary haemopoiesis, before the spinal cord is irreversibly damaged is stressed.

Correspondence: Dr D. Chanmugam, Department of Medicine, Faculty of Medicine, Colombo 8, Sri Lanka.

\section{Introduction}

Extramedullary haemopoiesis (EMH) occurs as a compensatory phenomenon in diseases of the haemopoietic system such as congenital haemolytic anaemias (Dawson, 1931), myelofibrosis (Close, Taira and Cleaveland, 1958), pernicious anaemia (Lyall, 1935) and infiltrations of the bone marrow with secondary malignancy (Plonskier, 1930). The common sites of occurrence of EMH are liver, spleen, kidneys and lymph nodes, and rarely the paravertebral region of thorax, retroperitoneal tissue, adrenals, pleura, falx cerebri, dura of the skull and spinal canal. 